\title{
PENGGUNAAN METODE PHONETIC DALAM PEMBELAJARAN KOSA KATA
} BAHASA ARAB

\author{
Amirul Mukminin, ${ }^{1}$ Khoirul Anwar, ${ }^{2}$ M. Budi Amin Amri ${ }^{3}$ \\ Universitas Ibrahimy Situbondo \\ ${ }^{1}$ mora.mukmin@gmail.com, ${ }^{2}$ mas_anwar78@yahoo.co.id, ${ }^{3}$ amrialampenani@gmail.com
}

\begin{abstract}
ion
Some methods are developed and applied in various institutions for improving the quality of student learning outcomes. Likewise, in the Arabic Development Institute (LPBA) Pondok Pesantren Salafiyah Syafi'iyah Sukorejo Situbondo which applies the Phonetic Method in the learning, especially in Arabic vocabulary learning. In the application, 1) teacher prepares a learning tools, 2) the learning is begun by a simple Arabic vocabulary expressions, 3) it is Helped by a classroom equipment as a media aid, and 4) teacher always provides a practical exercises at the end of learning.
\end{abstract}

Keyword: Phonetic Method, Arabic Vocabulary

\section{PENDAHULUAN}

Bahasa adalah alat komunikasi bagi manusia. Dengan bahasa, manusia bisa berinteraksi serta berkomunikasi antara individu dan individu lainya. Dengan begitu, mereka akan memahami maksud dan tujuan yang mereka kehendaki.

Bahasa Arab bisa diekspresikan secara lisan maupun tulisan. Namun demikian, bahasa lisan bisa dipandang sebagai hakikatnya sebuah bahasa. ${ }^{1}$ Realitas ini dapat dipahami dalam bentang sejarah peradaban manusia itu berbahasa secara lisan, meski sebagian dari mereka tidak menulis atau tidak mengenal lambang tulisan. Dengan kata lain, terkadang ditemukan adanya manusia mampu berko-munikasi secara lisan dengan lancar, padahal ia buta huruf, tidak bisa baca tulis. Sebagaimana firman Allah SWT. yang berbunyi:

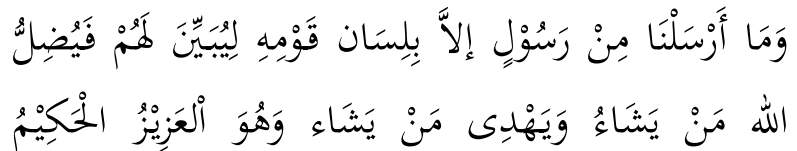

$$
\text { (إبراهيم : () (1) }
$$

\footnotetext{
${ }^{1}$ Rudliyah Zainuddin et.al, Metodologi dan Strategi Alternatif Pembelajaran Bahasa Arab (Yogyakarta: Pustaka Raihlah Group, 2005), 11.
}

Artinya: Kami tidak mengutus seorang rasulpun, melainkan dengan bahasa kaumnya, supaya ia dapat memberi penjelasan dengan terang kepada mereka. Maka Allah menyesatkan yang Dia kehendaki dan memberi petunjuk kepada siapa yang Dia kehendaki. Dan Dia-lah Tuhan yang Maha Kuasa lagi Maha Bijaksana. ${ }^{2}$

Maksud dari ayat tersebut ialah menggunakan kata lisan dalam berkomunikasi, agar pesan yang disampaikan dapat lebih mudah dan langsung dipahami maknanya oleh masyarakat atau sasaran. ${ }^{3}$

Al-Qur'an dan bahasa Arab bagaikan dua sisi mata uang yang tidak dapat dipisahpisahkan antara satu dengan yang lainnya. Mempelajari bahasa arab adalah syarat wajib untuk mengetahui al-Qur'an dan mempelajari al-qur'an bererti mempelajari bahasa Arab. Dengan demikian, juga sebagai alat komunikasi manusia beriman kepada Allah

2 Departemen Agama RI, Al-Qur'an dan Terjemahannya,(Bandung: CV Penerbit, Al-Jumanatul 'Ali, 2015), 255.

${ }^{3}$ Ibid, 12. 
yang terwujud dalam bentuk sholat, do'a-do'a dan sebagainya. ${ }^{4}$

Demikian dalam hal tersebut sesuai dengan ayat Al-Qur'an yang berbunyi :

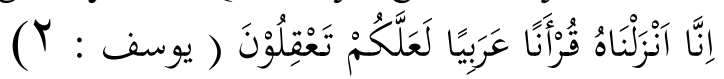

Artinya: Sesungguhnya Kami menurunkannya berupa Al Qur'an dengan berbahasa Arab, agar kamu memahaminya. ${ }^{5}$

Apabila kita merujuk pada ayat tersebut, maka bisa diambil suatu kesimpulan bahwa mempelajari bahasa Arab adalah syarat untuk memahami isi Al-Qur'an dan mempelajari Al-Qur'an berarti mempelajari bahasa Arab. Dengan demikian, maka peran bahasa Arab disamping sebagai alat komunikasi antara sesama manusia juga sebagai alat komunikasi antara hamba dan khaliqnya dalam bentuk shalat dan do'a-do'a.

Metode mengajar adalah alat yang merupakan bagian dari perangkat alat dalam pelaksanaan suatu strategi belajar mengajar. Oleh karena itu, belajar mengajar merupakan sarana atau alat untuk mencapai tujuan-tujuan belajar, maka metode mengajar merupakan alat pula untuk mencapai tujuan belajar. ${ }^{6}$

Dalam program bahasa Arab atau bahasa asing lainya yang sering menjadi sorotan adalah dari segi metode. Dalam tataran rialitas, pengajaran bahasa Arab, masih banyak guru bahasa Arab yang belum memiliki kapasitas yang seimbang antara "kemampuan berbahasa" dengan "kemampuan metodenya". Dengan kata lain, banyak guru yang memiliki kemampuan berbahasa yang baik, namun tidak dapat menentukan yang sesuai dengan materi, karakter dirinya dan peserta didiknya. ${ }^{7}$ Padahal sukses atau tidaknya suatu program pengajaran khususnya bahasa sering kali dinilai dari segi metode yang digunakan,

\footnotetext{
${ }^{4}$ Tayar Yusuf dan Saiful Anwar, Metodologi Pengajaran Agama Dan Bahasa Arab (Jakarta:PT.Rajawali Pers, 1995 ), 188.

5 Departemen Agama RI, al-Qur'an dan Terjemahannya ( Badung: PT. Mizan,2015), 235.

6 J.J Hasibun, Dip, ED. Dan Moedjiono ,Proses Belajar Mengajar (Bandung: PT. Remaja Rosdakarya, 2009), 13.

Ruyadli Zainuddin, Metodologi dan Strategi Alternatif Pembelajaran Bahasa Arab, 24
}

sebab metodelah yang menentukan isi dan cara mengajarkan bahasa.

Lembaga Pengembangan Bahasa Arab (LPBA) Pondok Pesantren Salafiyah Syafi'iyah Sukorejo Situbondo telah menerap-kan metode Phonetic dengan mementingkan Aspek latihan lisan (pengucapan) dan pendengaran dalam pembelajaran kosa kata Arab di Marhalah Ula, dengan tujuan untuk mempermudah siswa dalam pengucapan kosa kata bahasa Arab, karena siswa yang berada di Marhalah Ula belum pernah belajar bahasa Arab, sangat lemah dalam segi pengucapannya. Oleh karena itu Kopetensi Dasar (KD) yang harus dicapai di Marhalah Ula ini adalah bagaimana siswa bisa mengucapkan kosa kata dengan baik dan benar.

Dengan demikian penggunaan Metode Phonetic ini sangat cocok untuk siswa Marhalah Ula dalam belajar kosa kata Arab karena bisa mengenal kosa kata atau mufradat serta bisa menirukan ungkapan kosa kata tersebut dengan baik dan benar menggunakan bahasa Arab fusha.

Penelitian ini dilaskanakan di Lembaga Pengembangan Bahasa Arab (LPBA) Pondok Pesantren Salafiyah Syafi'iyah Sukorejo Situbondo karena terdapat beberapa keunikan dalam proses pembelajarannya, khususnya dalam pembelajaran mufradad bahasa Arab. Diantara keunikan tersebut adalah cepatnya santri dalam menghafal dan menerapkan mufradad tersebut dalam kehidupan seharihari. Disamping sarana dan prasarana yang cukup memadai, sehingga para siswa merasa nyaman ketika belajar. Juga penggunakan metode pembelajaran yang tepat sasaran, dimana pada lembaga tersebut menggunakan Metode Phonetic yang sangat efektif dan efesien untuk sistem pembelajaran khususnya di bidang pendidikan bahasa Arab pemula.

Penelitian ini bertujuan untuk mendeskripsikan dan menganalisis penggunaan metode Phonetic dalam pembelajaran kosa kata bahasa Arab, dan juga bagaimana kemampuan kosa kata bahasa Arab siswa setelah menggunakan metode tersebut. Berdasarkan hal tersebut, permasalahan dalam penelitian ini berupa bagaimana penggunaan 
metode Phonetic dalam pembelajaran kosa kata bahasa Arab di LPBA Pondok Pesantren Salafiyah Syafi'iyah Sukorejo Situbondo? Dan bagaimana kemampuan kosa kata bahasa Arab siswa setelah menggunakan metode phonetic di LPBA Pondok Pesantren Salafiyah Syafi'iyah Sukorejo Situbondo?

Metode penelitian yang digunakan adalah kualitatif, karena penelitian dilakukan secara mendalam dan menganilis dengan tajam tentang fenomena yang terjadi di lapangan berkatian dengan penggunaan metode Phonetic dalam pembelajaran kosa kata bahasa Arab di LPBA Pondok Pesantren Salafiyah Syafi'iyah Sukorejo Situbondo. Dan Teknik pengumpulan data menggunakan obserfasi, wawancara mendalam, dan dokumentasi.

\section{TEMUAN PENELITIAN DAN PEMBAHASAN}

Pada pembahasan ini, berisi analisa data atau penafsiran data-data yang telah ditemukan di lapangan terkait penggunaan metode Phonetic dalam pembelajaran kosa kata bahasa Arab Lembaga Pengembangan Bahasa Arab (LPBA) Pondok Pesantren Salafiyah Syafi'iyah Sukorejo Situbondo.

Secara garis besar, temuan-temuan di lapangan dapat dianalisa sebagai berikut:

1. Penggunaan Metode Phonetic dalam Pembelajaran Kosa Kata Bahasa Arab

a. Perencanaan Pembelajaran

Perencanaan Pembelajaran merupakan rencana atau kegiatan pembelajaran untuk setiap unit atau pertemuan pembelajaran. Perencanaan terdiri dari dua bagian, yaitu: pertama, penguasaan konsep atau teori pembelajaran termasuk jenis-jenis keterampilan dasar mengajar. Kedua, persiapan fisik yaitu menyangkut dengan sarana dan prasarana pembelajaran yang akan mendukung terlaksananya pembelajaran. Salah satu kelengkapan yang sifatnya fisik dan harus dipenuhi dalam pembelajaran yaitu membuat Rencana Pelaksanaan Pembelajaran (RPP) di dalamnya terdiri dari beberapa unsur-unsur yang meliputi tujuan, materi, metode, media, dan evaluasi. Pembelajaran yang dibuat oleh guru pada dasarnya merupakan langkah awal untuk melakukan salah satu jenis keterampilan mengajar melalui pembelajaran kosa-kata bahasa Arab. Berhasil atau tidaknya suatu kegiatan tergantung pada perencanaannya.

Adapun perencanaan pembelajaran dalam pembelajaran kosa kata Arab dengan menggunakan methode Phonetic di Lembaga Pengembangan Bahasa Arab (LPBA) Sukorejo yang ditemukan oleh peneliti di lapangan yaitu :

1) Mempersiapkan Rencana Pelaksanaan Pembelajaran (RPP) serta buku ajar.

2) Mempersiapkan bahan-bahan yang berkaitan dengan Metode Phonetic.

3) Penguasaan materi dengan cara mengulang/methola'ah sebelum mengajar.

Paparan di atas sejalan antara teori dan kenyataan di lapangan, terjadi kesamaan dalam perencanaan pembelajaran kosa-kata Bahasa Arab dengan menggunakan metode phonetic.

b. Pengelolaan Kelas

Berdasarkan buku Metodologi Pembelejaran Bahasa Arab (Ahmad Izzan), metode Phonetic adalah pembelajaran yang mengutamakan hear training dan speak training. Yaitu cara menyajikan pelajaran bahasa asing melalui latihan-latihan mendengarkan kemudian diikuti dengan latihanlatihan mengucapkan kata-kata dan kalimat dalam bahasa asing yang sedang dipelajari. ${ }^{8}$

Dalam proses pembelajaran, tentunya guru menginginkan kelasnya efektif dan efisien. Seperti yang dilakukan oleh guru Lembaga Pengem-bangan Bahasa Arab (LPBA) Pondok Pesantren Salafiyah Syafi'iyah, khususnya dalam

${ }^{8}$ Ahmad Izzan, Metodologi Pembelajaran Bahasa Arab. (Bandung: Humaniora, 2009), 91. 
pembelajaran kosa kata bahasa Arab sebagai contoh penggunaan metode Phonetic. Dimana dalam penggunaannya guru lebih mengutamakan aspek pengucapan atau lisan agar siswa tidak pasif, artinya lebih aktif dari guru yang bersangkutan. Seperti yang dilakukan oleh Ustadz Abdul Mu'is selaku guru bahasa Arab yang menggunakan metode tersendiri dalam pembelajaran bahasa Arab.

Metode yang digunakan Ustadz Abdul Mu'is di Lembaga Pengembangan Bahasa Arab (LPBA) Pondok Pesantren Salafiyah Syafi'iyah dalam pembelajaran kosa kata bahasa Arab untuk menciptakan siswa aktif dan kelas yang kondusif yakni, metode Phonetic.

Dari uraian diatas, metode yang digunakan oleh guru bahasa Arab di Lembaga Pengembangan Bahasa Arab (LPBA) Sukorejo dapat menciptakan siswa aktif dan efisien dan kelas menjadi kondusif.

c. Langkah-langkah Metode Phonetic

Dalam buku Metodologi Pembelejaran Bahasa Arab dijelaskan tentang langkah-langkah penggunaan metode Phonetic: sebagaimana beikut:

1) Guru membacakan bacaan bahasa asing di depan kelas, atau menghidupkan radio atau kaset, siswa mendengarkan dan mempraktikkan baik-baik acara bacaan dengan cermat, dan serius.

2) Seri-seri dalam bacaan disusun hingga menjadi bacaan yang sempurna atau berkelanjutan.

3) Guru dapat mengehentikan seriseri pelajaran tertentu jika seri pelajaran tersebut sudah dianggap selesai dan dikuasai anak didik, kemudian dilanjutkan pada session berikutnya.

4) Setelah pembelajaran membaca selesai, latihan percakapan dapat dilakukan dimulai dari yang sederhana, setelah itu menuju pada percakapan yang lebih sulit.
5) Untuk memperjelas ucapan atau percakapan, metode ini dianjurkan memakai media pengajaran.

6) Pada setiap akhir materi pelajaran, guru hendaknya memberikan latihan-latihan praktis dan latihan percakapan pada setiap anak didik. $^{9}$

Adapun tahap-tahap penggunaan metode Phonetic dalam pembelajaran kosa kata bahasa Arab di Lembaga Pengembangan Bahasa Arab (LPBA) Pondok Pesantren Salafiyah Syafi'iyah yang ditemukan oleh peneliti di lapangan, sebagai berikut:

a) Guru menghidupakan radio yang berisi kosa kata bahasa Arab di depan kelas, siswa mendengarkan baik-baik bacaan tersebut secara cermat. Kemudian mengulang bacaan tersebut dengan memperhatikan makhraj dari huruf-huruf hijaiyah tersebut.

b) Guru menghentikan seri-seri pelajaran jika pelajaran tersebut sudah dianggap selesai dan diikuti oleh peserta didik dengan baik dan benar. Selanjutnya dilanjutkan pada seri berikutnya.

c) Setelah pelajaran membaca selesai. Kemudian latihan percakapan dapat dilakukan bersama teman dengan berpasangan.

Dengan ini, peneliti dapat menyimpulkan bahwa antara teori dan kenyataan di lapangan terjadi kesamaan dalam penggunaan metode Phonetic dalam pembelajaran kosa kata bahasa Arab.

Hal ini sesuai dengan buku karangan Ahmad Muhtadi Anshor "Pengajaran Bahasa Arab; Media dan Metode-metodenya", bahwa metode Phonetic dalam praktiknya menggunakan hear training dan speak training, yaitu cara menyajikan materi (bahasa asing) melalui latihan mengucapkan kata-kata dan kalimat 
dalam bahasa asing yang sedang dipelajari. $^{10}$

2. Kemampuan Kosa Kata Siswa setelah Menggunakan Metode Phonetic

Kemampuan belajar ialah suatu penilaian akhir dari proses dan pengenalan yang dilakuakan berulang-ulang. Serta akan tersimpan dalam jangka waktu lama atau bahkan tidak akan hilang selamalamanya, karena kemampuan turut serta dalam membentuk pribadi individu yang selalu ingin mencapai hasil yang lebih baik, sehingga akan merubah cara berpikir serta menghasilkan prilaku kerja yang lebih baik.

Dalam kemampuan kosa-kata
siswa setelah menggunakan Metode Phonetic, terdapat beberapa upaya sehingga proses pelaksanaan belajar mengajar dapat terlaksana dengan efektif dan efesien, salah satunya ialah dengan evaluasi berupa memberikan tugas atau pelatihan baik itu tertulis maupun dengan bentuk langsung, hal ini dilaksanakan dalam rangka agar siswa dapat bebas melihat bagaimana kemampuan peserta didiknya, baik dalam aspek pengetahuan tingkahlaku dan perkembanagannya.

Setelah menggunakan metode phonetik, hasilnya tanpak berbeda dengan sebelumnya, yang mana pada mulanya santri tidak antosias dalam belajar, menjadi antosias. Sehingga hal ini memicu akan kemampuan mereka dalm memahmi pelajaran. Pada mulanya mereka lambat menghafalkan mufradad, menjadi cepat. Dan juga hal ini tanpak dalam pembelajaran, yang mana mereka sudah dapat menggunakan bahasa Arab secara aktif.

Berdasarkan uraian di atas dapat disimpulkan bahwa pembelajaran kosakata bahasa Arab dengan Mengguanakan Metode Phonetic sangatlah cocok untuk menarik siswa sehingga mereka bersemangat dalam belajar serta untuk meningkatkan kemampuan belajarnya dengan melalui Metode Phonetic sebagai penujang dalam keaktifan proses pembelajaran.

\section{SIMPULAN}

Berdasarkan kajian teoritik yang dilanjutkan dengan penyajian data dan analisa data, dapat disimpulkan sebagai berikut:

Penggunaan Metode Phonetic dalam pembelajaran kosa kata bahasa Arab di Lembaga Pengembangan Bahasa Arab (LPBA) Pondok Pesantren Salafiyah Syafi'iyah Sukorejo Situbondo, yaitu guru mempersiapkan perangkat pembelajaran, pembelajaran dimulai dengan ungkapanungkapan kosa kata bahasa Arab sederhana, dibantu dengan peralatan kelas sebagai media bantu, dan setiap akhir pembelajaran guru memberikan latihan praktis.

Penggunaan metode Phonetic dalam pembelajaran kosa kata dapat meningkatkan kemampuan kosa kata siswa. Karena metode ini memberikan latihan langsung atau tugas baik berupa tulisan atau praktek secara langsung. Dengan demikian guru bisa melihat langsung bagaimana kemampuan siswa baik dalam pengetahuan, sikap dan pengembangan studi bahasa Arab.

\section{Daftar Pustaka}

Ahmad Izzan, Metodologi Pembelajaran Bahasa Arab. (Bandung: Humaniora, 2009)

Ahmad Muhtadi Anshor, Pengajaran Bahasa Arab; Media dan Metode-metodenya (Yogyakarta: Teras, 2009)

Departemen Agama RI, Al-Qur'an dan Terjemahannya,(Bandung: CV Penerbit, Al-Jumanatul 'Ali, 2015)

J.J Hasibun, Dip, ED. Dan Moedjiono, Proses Belajar Mengajar (Bandung: PT. Remaja Rosdakarya, 2009)

Rudliyah Zainuddin et.al, Metodologi dan Strategi Alternatif Pembelajaran Bahasa Arab (Yogyakarta: Pustaka Raihlah Group, 2005)

Tayar Yusuf dan Saiful Anwar, Metodologi Pengajaran Agama Dan Bahasa Arab (Jakarta:PT.Rajawali Pers, 1995 )

10 Ahmad Muhtadi Anshor, Pengajaran Bahasa Arab; Media dan Metode-metodenya (Yogyakarta: Teras, 2009), 71. 